\title{
BIBLIOGRAPHIC REVIEW FACTORS INFLUENCING PATIENT'S ANESTHETIC SATISFACTION
}

KEY WORDS: satisfaction, anesthesia, general anesthesia, regional anesthesia, quality.

\section{José Luis} Sànchez

Md General Practitioner Postgraduate Anesthesiology, Victoria Nohemí Chang Huang Md Anesthesiologist.

Objective: Collect scientific evidence on the factors that influence the anesthetic satisfaction of patients, through a theoretical bibliographic review. Obtain an updated compendium of studies on user satisfaction, the instruments used to measure it and the influencing factors, which will be of great use to anesthesiology services to establish the actions that contribute to increasing satisfaction and the quality of the service provided.

Materials and Methods: Theoretical-descriptive review. Scientific articles were used as primary sources of information, the analysis material was collected from the following databases (secondary sources): Pubmed, Scielo, Wiley Online Library, Biomed Central. Articles on satisfaction of surgical patients in anesthesiology services were included, from 2016 to 2021 .

Results: 41 articles were identified, including only 20 studies. Anesthetic satisfaction in the researches consulted was high. When analyzing the factors related to satisfaction, most of the researches consulted highlight that they are various and depend on the healthcare professional, the patient and the healthcare institution. The most important factors are the side effects that patients experience after anesthesia, such as nausea and vomiting. Validated instruments such as QoR15, EVAN-G, LA-EQ, PSQ-2 or PQRS and others created for this purpose were used.

Conclusion: Patient satisfaction with anesthesia is an aspect of utmost importance in the context of the quality of anesthesiology services.

\section{INTRODUCTION}

The quality of health care has been defined as the degree to which health services increase the likelihood of the desired health outcome. Patient satisfaction has been defined as the benchmark that indicates the level at which patient expectations and the quality of medical care are met 1 .

Patient satisfaction is an important subjective measure of the quality of medical care that contributes to the evaluation of the structure, process, and outcome of services. Many factors contribute, including institutional structure, interpersonal relationships, and patient expectations 2. Age, gender, social security, educational and social status also play a role. The key factor is adequate perioperative information between the patient or her family and healthcare providers 3 .

The degree of patient satisfaction is an important indicator of the outcome of medical care and of the evaluation of the quality of services in anesthesiology. However, it is difficult to evaluate this result because satisfaction is a multidimensional concept with determinants that are not yet clearly defined. Although the role of patient satisfaction in anesthetic care has been increasingly investigated, many studies use only simple general questions to assess it, leading to high scoring results 4,5.The reliability of the global satisfaction ratings for a single item is poor and inadequate to address the complexity of this variable 6.

It is generally accepted that safe and effective pain relief contributes directly to satisfaction: the better the pain relief, the greater the satisfaction 7. Patient satisfaction is a subjective and challenging perception that links physical, expressive factors, psychological, social and cultural. Dissatisfaction occurs if the patient feels an inconsistency between the care expected and that provided. Due to the complexity, duration of surgery and pathophysiology of the disease, it is difficult to measure patient satisfaction related to perioperative anesthesia care. 8. According to many studies, levels of medical satisfaction are above $85 \%$ and satisfaction of the patient in terms of anesthesia is not very different 9 .

At present it is considered that anesthesiologists have a greater participation in the preoperative evaluation and postoperative care, which may allow the prior identification and treatment of the adverse effects of this period. patient confidence through detailed discussion of the anesthetic plan and response to any concerns about anesthesia; therefore, visiting him and discussing perioperative anesthesia problems, as well as resolving his concerns significantly improve patient satisfaction, regardless of the type of anesthesia performed ${ }^{11}$.

Anesthesiology services will benefit from the above ideas about the results found in this research, since it will have a summary of the evidence about patient satisfaction with the service, the instruments used to measure it and the factors that influence this. This will allow to draw up strategies to increase the quality of the service and the satisfaction of the patients.

Consequently, the objective of this research is to collect up-todate scientific evidence on the anesthetic satisfaction of surgical patients and the influencing factors, for which a theoretical bibliographic review will be carried out. With this review, an updated compendium of evidence of anesthetic satisfaction of patients was obtained, the instruments used to measure it and the factors that influence it, which will be of great use to anesthesiology services to establish actions that contribute to the increased satisfaction and quality of the service provided.

\section{MATERIALS AND METHODS}

Study design: a theoretical review, of a documentary type, was carried out.

Information sources: the following were used as primary information sources: scientific articles from indexed journals and as secondary information sources, specialized databases were taken into account: Pubmed, Scielo, Wiley Online Library or Biomed

Search criteria: the following Mesh Terms and Boolean operators were used: "Satisfaction" OR "patient satisfaction" OR "patient preference" AND "anesthesia" OR "anesthetic services" OR "anesthetic evaluation" OR "general anesthesia" OR "regional anesthesia "AND" healthcare evaluation "OR" healthcare quality assessment "AND" elective surgery "OR" emergency surgery "OR" laparoschopic surgery "OR" open surgery "AND" English (lang) "OR" Spanish (lang) ".

\section{Selection criteria:}

Inclusion Criteria:

- Articles on patient satisfaction with the anesthesiology service. 
- Research carried out with adults ( $\geq 18$ years).

- Articles in Spanish and English.

- Articles published from 2016 to April 2021.

- Analytical, observational, cohort design, systematic reviews and meta-analysis.

- Research carried out with elective surgery and emergency patients.

- Studies of patients who received general or regional anesthesia.

\section{Exclusion Criteria:}

- Research without bioethical statements.

- Incomplete articles.

- Investigations with unclear methodology, not reproducible.

\section{METHODOLOGY:}

a bibliographic search was carried out in specialized databases, using the search terms already described. The abstracts of the articles were read and downloaded. Once the articles had been identified, they proceeded to their detailed analysis, collecting in a data matrix information on author / $\mathrm{s}$, year of publication, country, journal, database, characteristics of the analyzed population, degree of satisfaction, instrument used to measure satisfaction and factors that influence patient satisfaction with the anesthesiology service. Consecutively, the writing of the high-level scientific article began, using the Mendeley bibliography manager. Subsequently, the results, discussion and conclusion were elaborated.

\section{RESULTS}

41 articles were identified in the search carried out, of which 7 were eliminated for having been carried out with patients under 18 years of age, 4 that were published before 2016, 3 for having an unclear methodology and difficult to reproduce, 2 theses degree, 3 articles without ethical statements and 2 for studying satisfaction with obstetric anesthesia. At the end of the selection process, only 20 articles were identified, from which this theoretical review was carried out. Most of the selected articles were published in 2017 and 2019 ( $n=7$; $35 \%$ ) respectively and $20 \%$ were published in Turkey $(n=4$; $20 \%$ ). See tables 1 and 2 .

\section{The findings found in relation to the subject studied are} described below:

\section{Degree of anesthetic satisfaction}

The degree of anesthetic satisfaction in the researches consulted was high $3,8,9,12-18$. When analyzing satisfaction for regional and general anesthesia, various results were obtained. In some studies, satisfaction was higher with regional anesthesia 19 than with general anesthesia 20 . Research describing the use of non-pharmacological interventions, such as music therapy, was also evidenced. , which can increase patient satisfaction with anesthesia 21,22. Other studies defend a high degree of acceptance of general anesthesia among older adults 23 . See table 3 .

For his part, the author Tosuner 3 analyzed the degree of satisfaction with regional anesthesia in a series of 300 cases. The general level of satisfaction with regional anesthesia was $82.3 \%$. In contrast, Berning et al. 8 describe $94.6 \%$ of anesthetic satisfaction and determined that the quality of postoperative recovery has little effect on the degree of satisfaction. And a study conducted in Ethiopia by Benwu et al. 9 reported $83.3 \%$ anesthetic satisfaction.

Likewise, four authors 12-15 describe a higher degree of satisfaction with regional anesthesia than with general anesthesia, however, Arenholt et al. 16 determined that $98.9 \%$ satisfaction with local anesthesia in patients who underwent surgery to fix the spinous sacral ligament.

Similarly, the group of researchers from Mracek et al. 17 who investigated the degree of satisfaction with general anesthesia found that in $93.1 \%$ of the patients studied, it was higher than satisfaction with regional anesthesia (65.2\%) in relation to those who underwent carotid endarterectomy. However, Wang et al. 18 describe a higher degree of satisfaction among patients who received general anesthesia compared to those who received regional anesthesia, in fusion surgery and anterior cervical discectomy.Factores condicionantes de la satisfacción con la anestesia

When analyzing the conditioning factors of satisfaction with anesthesia, most of the researches consulted highlight that there are several and they depend on the healthcare professional, the patient and the healthcare institution. Similarly, the most important factors for satisfaction include the side effects suffered by patients after anesthesia, nausea and vomiting being among the most frequent 9,12,17,19. Likewise, most researchers agree that female sex and high educational level are factors that are related to a lower degree of satisfaction with anesthesia 3,9. See table 4.

For his part, the author Tosuner 3 mentions that the degree of satisfaction with anesthesia is higher in the age group 18-25 years, male, previous experience of having received regional anesthesia and that they were well informed about regional anesthesia in a preoperative anesthetic evaluation. There was a relationship between pain due to failed spinal anesthesia during surgery and dissatisfaction with regional anesthesia.

While Benwu et al. 9 observed that the factors that affected the degree of satisfaction with anesthesia were: female sex, higher educational level, use of regional anesthesia, presence of nausea, vomiting, pain, dyspnea and cold in the immediate postoperative period and, as a factor that increases the satisfaction describe effective communication with the anesthesiologist in the preoperative period.

Within this same framework, Wang et al. 18 state that among the factors that favor anesthetic satisfaction is that regional anesthesia may be insufficient versus general anesthesia, since the patients reported pain during surgery; Furthermore, in cervical discectomy, one of the most important adverse effects with regional anesthesia is Horner's syndrome.

On the other hand, three authors $21,22,24$ assure that nonpharmacological strategies, based on an improvement in communication between the anesthesiologist and the patient, and intraoperative music therapy, considerably increase the degree of satisfaction with the service.

Mracek et al. 17 and Schiefer et al. 25 determined that the factors that affected the degree of satisfaction were postoperative nausea and vomiting and fear of anesthesia in the group that received general anesthesia, while among those that received regional anesthesia, the main factor of non-satisfaction was the intraoperative pain.

Wazir et al. 26 describe, among the determinants of anesthetic satisfaction, factors related to the professionals and the health institution. Effective communication with the patient, spending more time with the patient, the skills of the professional, empathy and extraverbal language are some of the factors related to the professionals that influence the degree of patient satisfaction. In addition, it is known that high educational level, female sex, marital status or social class, are factors that also influence satisfaction. Likewise, health institutions with a high degree of hygiene, availability of personnel and resources, also contribute to increase patient satisfaction in the postoperative period.

Sinbukhova and Lubnin 23 describe as factors that affected satisfaction in geriatric patients: excess anxiety before surgery about the operation and anesthesia, the fact that the anesthesiologist does not visit the patient pre and 
postoperatively, insufficient attention from the anesthesi ologist in the operating room before anesthesia and the presence of nausea, vomiting, pain, dizziness, general malaise and thirst in the immediate postoperative period.

Additionally, Greimel et al. 27 in a series of 15,326 patients who underwent knee arthroplasty, which measured postoperative pain, need for analgesics, and satisfaction with the anesthesiology service; it was concluded that the factors favoring anesthetic satisfaction were the use of a combination of general and spinal anesthesia. Furthermore, the use of a combination of general and regional anesthesia was associated with a very significant advantage over other anesthetic techniques with respect to perioperative pain management, with low reports of side effects and greater subjective well-being. The use of regional anesthesia or the combination of general and regional was associated with higher degrees of satisfaction when compared with general anesthesia alone. This higher degree of satisfaction was associated with the lower need for the use of analgesia in the postoperative period, faster functional recovery and overall satisfaction.

Instruments to measure anesthetic satisfaction in surgical patients Regarding the instruments used to measure the degree of satisfaction with anesthesia, the researches consulted describe some that have been previously validated, such as QoR-15 ("Quality of recovery-15"), EVANG (Evaluation du Vecu de l'Anesthesie Generale), CSQ-8 ("Client Satisfaction Questionnarie-8"), PSQ-2 or PQRS ("Physicisian Quality Reporting System"), m-PSI ("Modified Patient Satisfaction Index") 8,12,13 , 16,18,21-23,25,28; while other authors created their own instruments to measure satisfaction $3,9,17,19,20,24,26$. See table 5 .

Tosuner et al. 3 applied a questionnaire on regional anesthesia to determine patient satisfaction and mood during the procedure. Patients could only mark one option: satisfied or dissatisfied. In the study by Berning et al. 8 used the questionnaire validated by Stark et al. 29 "Quality of recovery15" QoR-15, which provides a valid, reliable, responsive and easy-to-use method to measure the quality of a patient's postoperative recovery.

In contrast, Benwu et al. 9 prepared a structured questionnaire previously tested by reviewing previously conducted studies on the subject of a prospective study on the satisfaction of the elective surgical hospitalized patient with the perioperative anesthesia service.

De los Ríos et al. 12 used in their research the Postoperative Recovery Quality Scale (PQRS), which includes an assessment of the physiological domains (cold, thirst, nausea, vomiting, pain) and, in addition, they used a verbal numerical rating scale (VNR), in which when obtaining more than 5 points, it indicated that the patient was satisfied with the anesthesia received.

To measure the degree of satisfaction, Kreutziger et al. 13 used the German version of the customer satisfaction questionnaire (CSQ-8), which consists of eight questions (items); each provides a Likert-type scale with four response levels numbered 1 through 4. Agreements have low-level numbers ( 1 and 2$)$ and disagreements have higher-level numbers ( 3 and 4). Overall satisfaction is reflected in the sum of the level numbers; therefore, the lower the number, the greater the patient satisfaction.

In other research by Arenholt et al. 16 who used the local anesthetic intraoperative experience questionnaire (LA-EQ) to evaluate the patient's experience with local anesthesia, who had undergone surgery to fix the spinous sacral ligament. The LA-EQ was developed to assess the patient's experience with carotid endarterectomy performed under local anesthesia. The aspects that are evaluated with this questionnaire are: previous experiences of surgery with local anesthesia, discomfort at the time of injection, pain and discomfort during surgery, nervousness and difficulty in staying calm during surgery.

In the research by Mracek et al. 17 the instrument was designed to assess satisfaction. It is a simple questionnaire, which the patients answered at the time of discharge. This questionnaire inquired about satisfaction with the anesthesia received and, if they needed a new surgery, they were asked if they would choose the same form of anesthesia again.

Tosuner et al. 3 applied a questionnaire on regional anesthesia to determine patient satisfaction and mood during the procedure. Patients could only mark one option: satisfied or dissatisfied. In the study by Berning et al. 8 used the questionnaire validated by Stark et al. 29 "Quality of recovery15" QoR-15, which provides a valid, reliable, responsive and easy-to-use method to measure the quality of a patient's postoperative recovery.

In contrast, Benwu et al. 9 prepared a structured questionnaire previously tested by reviewing previously conducted studies on the subject of a prospective study on the satisfaction of the elective surgical hospitalized patient with the perioperative anesthesia service.

De los Ríos et al. 12 used in their research the Postoperative Recovery Quality Scale (PQRS), which includes an assessment of the physiological domains (cold, thirst, nausea, vomiting, pain) and, in addition, they used a verbal numerical rating scale (VNR), in which when obtaining more than 5 points, it indicated that the patient was satisfied with the anesthesia received.

To measure the degree of satisfaction, Kreutziger et al. 13 used the German version of the customer satisfaction questionnaire (CSQ-8), which consists of eight questions (items); Each provides a Likert-type scale with four response levels numbered 1 through 4 . Agreements have low-level numbers (1 and 2) and disagreements have higher-level numbers ( 3 and 4). Overall satisfaction is reflected in the sum of the level numbers; therefore, the lower the number, the greater the patient satisfaction.

In other research by Arenholt et al. 16 who used the local anesthetic intraoperative experience questionnaire (LA-EQ) to evaluate the patient's experience with local anesthesia, who had undergone surgery to fix the spinous sacral ligament. The LA-EQ was developed to assess the patient's experience with carotid endarterectomy performed under local anesthesia. The aspects that are evaluated with this questionnaire are: previous experiences of surgery with local anesthesia, discomfort at the time of injection, pain and discomfort during surgery, nervousness and difficulty in staying calm during surgery.

In the research by Mracek et al. 17 the instrument was designed to assess satisfaction. It is a simple questionnaire, which the patients answered at the time of discharge. This questionnaire inquired about satisfaction with the anesthesia received and, if they needed a new surgery, they were asked if they would choose the same form of anesthesia again.

\section{DISCUSSION}

At present, it is considered that the patient-centered health system has quality of care among its objectives. Therefore, satisfaction is a key component of patient-oriented healthcare. Although the surgeon and the patient should be satisfied with the anesthesia, the goals are not the same. In fact, high satisfaction does not necessarily correspond to safe 
and effective care. Given the above, patient satisfaction as well as that of the surgeon should be two important objectives in current quality medicine in anesthesiology, which represent an index of safe and effective medical care 14.

In this research, it was observed that most of the authors consulted agree that the degree of satisfaction with anesthesia in surgical patients was high $3,8,9,12-18$, which means that, although the reported figures are very Depending on the instrument used and the type of patients studied, in general, it can be said that there is a high degree of satisfaction with anesthesia services.

This is explained because patient satisfaction with anesthesia is a complex concept, since it includes not only the level of satisfaction with the anesthesia itself but also the presence of fears, depression, worries, evaluation of the anes thesiologist's work, as well as dysfunction cognitive as a possible negative consequence of anesthesia 32; additionally, Castellanos et al. 33 ensure that the role of the anes thesiologist is not restricted to the operating room, but rather that its action is expected to transcend the operating room, with greater interaction with patients, in other services such as lithotripsy, endoscopy, electroconvulsive therapy, cardiac catheterization, among other procedures; Therefore, guaranteeing a quality service, with high levels of patient satisfaction, is essential.

Based on these considerations, some of the authors consulted describe higher levels of satisfaction with regional anesthesia than with general anesthesia 12-15. This mainly responds to the fact that with general anesthesia, important side effects are described more frequently, which can become disabling 16. These differences could be explained because satisfaction with anesthesia depends on several factors, including the previous experiences of the patients. patients, and communication with the anesthesiologist, resulting in the effect of the interaction of multiple variables, among which the immediate postoperative period also plays an important role 34 .

Consequently, it can be described that regional and general anesthesia is used depending on the type and duration of surgery. Each has advantages and disadvantages and can have distinctive effects on the perioperative outcome. The potential advantages of regional anesthesia include: the absence of airway instrumentation, deep analgesia, stable hemodynamics, less surgical blood loss, and therefore better operative conditions; however, reported disadvantages include: intraoperative anxiety, cough, hiccups, and movement. In contrast, general anesthesia leaves the patient immobile throughout the procedure and provides a safe airway, although it can cause hemodynamic instability and greater intraoperative blood loss, analgesic requirements, and postoperative nausea and vomiting 35.

Regarding the factors that influence patient satisfaction, several are described in this research that are related to the patients, the anesthesiologist and the institution. Most of the authors consulted agree that side effects, such as nausea and vomiting, or pain, reduce the degree of satisfaction. Furthermore, it is known that a very important factor in satisfaction depends on the ability of the anesthesiologist to generate empathy and achieve effective communication with patients; Additionally, most authors agree that other factors such as the sex, age or educational level of the patient also have an important influence on the level of satisfaction with anesthesia 3,9,12,17,19.

Additionally, it can be determined that most of the authors consulted agree that guaranteeing patient satisfaction is one of the main indicators of anesthesiology service quality and the recommendations they provide to achieve this include offering users the necessary information about anesthetics, their possible risks and side effects; likewise, allow them to participate in making decisions about the type of anesthesia they wish to receive; which is based on an adequate doctorpatient relationship with the anesthesiology staff, respect for their privacy during surgery and postoperatively, anxiety management in the preoperative period, and adequate postoperative pain control, among others $3,9,12,17,19$.

In any case, these aforementioned findings can also be supported by the retrospective study by Pozdnyakova et al. 36 in which 51,676 surgical patients were included and, where they also describe that the factors that most affected patient satisfaction were age $\geq 55$ years, surgery performed at night, or not being hospitalized. These authors acknowledge that many of the factors cannot be controlled.

For their part, Echevarría et al. 37 describe results that support the findings of this research. These authors, when conducting a survey on satisfaction with the anesthesiology consultation, which included 4006 patients, determined that the main factor influencing the degree of patient satisfaction is the communication skills of the anesthesiologist, in addition to respectful treatment, and the degree of information received during the consultation.

Despite the above, it can be stated that patient satisfaction with anesthesia is high, with differing opinions as to whether this satisfaction is higher among patients receiving general or regional anesthesia. The explanation for these divergences has been based on the presence of adverse events related to anesthesia (nausea, vomiting, pain, cold and urinary retention) and the time it takes for patients to regain their functional independence in the immediate postoperative period.

In addition, with this theoretical review the authors showed that the factors that determine satisfaction are several and diverse and include aspects related to the patient, the anesthesiology staff, the surgery and the health institution. Another finding of this review is that various instruments are used to measure patient satisfaction with anesthesia, some of these have been widely validated $8,12,13,16,18,21-23,25,28$, while others are less robust and were created only to analyze a specific case series $3,9,17,19,20,24,26$. These variations could be the explanation for the notable differences between the satisfaction reports observed in this research.

In this same context, this research showed that the degree of satisfaction of patients with anesthesia is high, however, as this is a multifactorial phenomenon and, when using various instruments to measure satisfaction, it is described that these results can be generalized, which constitutes one of the limitations of this research, in which, due to its theoretical review design, a quantitative analysis of the quality of the evidence (meta-analysis) was not performed.

Finally, it is worth mentioning the strengths and limitations found during the performance of this bibliographic review; Among the methodological strengths, the availability of specific scientific literature based on the search criteria used, updated studies in relation to the subject discussed, and categorization of the subject stand out. Likewise, within the limitations of this review, the need for larger-scale and betterdesigned studies can be mentioned.

\section{CONCLUTION}

Patient satisfaction with anesthesia is extremely important in the context of the quality of anesthesiology services. In the consulted literature, high levels of satisfaction are reported, as a result of several factors, related to the patient, the anesthesiologist and the institution; as well as the application of various instruments for its determination, many times 
created ad hoc and without validation. When analyzing satisfaction for regional and general anesthesia, diverse results were obtained. In some investigations, satisfaction was higher with regional anesthesia than with general anesthesia. In another study, it was determined that the combination of general and regional anesthesia achieved a high degree of satisfaction in patients. There is also research that describes the use of non-pharmacological interventions, such as music therapy, which can increase patient satisfaction with anesthesia.

\section{Authors' contribution}

The research protocol and its design, data collection, statistical analysis, data assessment and interpretation, critical analysis, discussion, writing and approval of the final manuscript were carried out by the authors, who contributed in the same way throughout the process. The corresponding author represents the collective of authors.

\section{Availability of data and materials}

The data supporting this manuscript are available upon request from the corresponding author.

\section{Consent for publication}

No specific consent was obtained for its publication, since it is a bibliographic review.

\section{Approval and consent}

The protocol was approved in a timely manner.

\section{Financing}

This research was funded exclusively by the authors, without receiving external funding.

\section{Declaration of conflict of interest}

The authors of this research declare that they have no conflict of interest.

\section{Table 1.Year of publication of the articles}

\begin{tabular}{|l|l|l|}
\hline Year & n & $\%$ \\
\hline 2016 & 1 & 5 \\
\hline 2017 & 7 & 35 \\
\hline 2018 & 2 & 10 \\
\hline 2019 & 7 & 35 \\
\hline 2020 & 2 & 10 \\
\hline 2021 & 1 & 5 \\
\hline Total & 20 & 100 \\
\hline
\end{tabular}

\section{Source: indexed journals}

Elaboration: authors

Table 2. Country of publication of the articles

\begin{tabular}{|l|l|l|}
\hline Country & $\mathbf{n}$ & $\%$ \\
\hline Turkey & 4 & 20 \\
\hline Sweden & 1 & 5 \\
\hline Ethiopia & 1 & 5 \\
\hline China & 2 & 10 \\
\hline Cuba & 1 & 5 \\
\hline Czech Republic & 1 & 5 \\
\hline India & 1 & 5 \\
\hline USA & 1 & 5 \\
\hline Tunisia & 1 & 5 \\
\hline Russia & 1 & 5 \\
\hline Germany & 2 & 10 \\
\hline Austria & 1 & 5 \\
\hline France & 1 & 5 \\
\hline Italy & 1 & 5 \\
\hline Denmark & 1 & 5 \\
\hline Total & 20 & $\mathbf{1 0 0}$ \\
\hline
\end{tabular}

Source: indexed journals

Elaboration: authors

Table 3. Degree of patient satisfaction with anesthesia

\begin{tabular}{|l|l|l|}
\hline Author/year & Type of anesthesia| & Satisfaction \\
\hline
\end{tabular}

\begin{tabular}{|l|l|l|}
\hline Tosuner et al., (2019). & Regional & $82,3 \%$ \\
\hline Berning et al., (2017). & General & $94,6 \%$ \\
\hline Menjie et al., (2019). & General & $83,3 \%$ \\
\hline De los Ríos (2017). & General & $78,6 \%$ \\
\cline { 2 - 3 } & Regional & $91,0 \%$ \\
\hline \multirow{2}{*}{ Mraceck et al., (2018). } & General & $93,1 \%$ \\
\cline { 2 - 3 } & Regional & $65,2 \%$ \\
\hline Subramanian et al., (2017) & General & $79,0 \%$ \\
\hline Uzman et al., (2019). & Regional & $94,0 \%$ \\
\hline Gökçek et al., (2020). & General & $73,3 \%$ \\
\hline Kahloul et al., (2017). & General & $81,4 \%$ \\
\hline Sinbukhova y Lubnin (2019). & General & $70,0 \%$ \\
\hline Capdevila et al., (2016). & Regional & $99,4 \%$ \\
\cline { 2 - 3 } & General & $94,4 \%$ \\
\hline Arenholt et al., (2019). & General & $98,9 \%$ \\
\hline
\end{tabular}

\section{Source: indexed journals}

Elaboration: authors

Table 4. Factors that determine satisfaction

\begin{tabular}{|l|l|}
\hline Author/year & Facts
\end{tabular}

Tosuner et al., Age: 18-25 years.

\begin{tabular}{l|l|l} 
(2019). & Male gender. & Male gender.
\end{tabular}

Previous regional anesthesia.

Adequate communication with the patient increases safety.

Berning et al., The quality of the recovery had little (2017). influence on the degree of satisfaction

Benwu et al., Nausea, vomiting, pain, dyspnea, and cold

(2019). $\quad$ Women had less satisfaction than men

The higher the educational level, the lower the satisfaction

Chuang et al., Effective communication is a non-

(2017). pharmacological tool that improves patient satisfaction

De los Ríos $\quad$ Thirst, cold, pain, nausea and vomiting.

(2017). $\quad$ These are more common in general anesthesia patients.

Mraceck et $\quad$ Postoperative nausea and vomiting,

al., (2018). postoperative psychological disturbances and fear of general anesthesia.

Intraoperative pain. Respiratory problems. Intraoperative stress and discomfort.

Subramanian Poorly managed postoperative pain et al., (2017)

Uzman et al., Headache, urinary retention, and pain in the (2019). $\quad$ right shoulder postoperatively

Wazir et al., Effective communication with the patient, (2018). spending more time with the patient, professional skills, empathy and extraverbal language

High educational level, female gender, marital status or social class, are factors that also influence satisfaction and concern patients

Gökçek et al., Pharmacological interventions such as music (2020). $\quad$ therapy

Sinbukhova y Anxiety before surgery about the operation Lubnin and anesthesia, no postoperative visit of the (2019). anesthesiologist, no visit of the anesthesiologist before the operation, insufficient attention of the anesthesiologist in the operating room before anesthesia, nausea, vomiting, pain, dizziness, general malaise and thirst.

Schifer et al., Nausea, postoperative pain management. (2019). Lack of information on anesthetic options.

\begin{tabular}{l|l} 
Greimel et & Less need for the use of analgesia in the
\end{tabular} al., (2017). postoperative period, faster functional recovery and overall satisfaction 


\section{Source: indexed journals \\ Elaboration: authors}

\section{REFERENCES}

1. Govere L, Govere EM. How Effective is Cultural Competence Training of Healthcare Providers on Improving Patient Satisfaction of Minority Groups? A Systematic Review of Literature. Worldviews Evidence-Based Nurs [Internet]. 2016 Dec 1 [cited 2021 Apr 19];13(6):402-10. Available from: https:// pub med.ncbi.nlm.nih.gov/27779817/

2. Manzoor F, Wei L, Hussain A, Asif M, Shah SIA. Patient Satisfaction with Health Care Services; An Application of Physician's Behavior as a Moderator. Int J Environ Res Public Health [Internet]. 2019 Sep 9 [cited 2021 Apr 19];16 (18): 3318-25. Available from: https:// pubmed. ncbi. nlm. nih. gov/31 505840/

3. Tosuner Akpinar V, Koroglu L, Gurbuz Aytuluk H. Rejyonel anestezide hastaların memnuniyeti ve duygu durumu ile ilgili faktörlerin de erlendirilmesi. Agri [Internet]. 2019 Apr 1 [cited 2021 Apr 19];31 (2):5762. Available from: https:// pubmed.ncbi.nlm. nih. gov/ 30995331

4. Bowyer A, Royse C. A matter of perspective - Objective versus subjective outcomes in the assessment of quality of recovery. Best Pract Res Clin Anaesthesiol [Internet]. 2018 Sep 1 [cited 2021 Apr 19];32(3-4):287-94. Available from:https://linkinghub.elsevier.com/ retrieve/ pii/S1521 689618 $30003 \mathrm{X}$

5. Bruder N, Auquier P. Integration of satisfaction and quality of recovery. Best Pract Res Clin Anaesthesiol [Internet]. 2018 Sep 1 [cited 2021 Apr 19];32 (3-4):277-86. Available from:https://pubmed.ncbi.nlm. nih. gov/ 30522718 /

6. Chantong P, Abrishami A, Wong J. Systematic review of questionnaires measuring patient satisfaction in ambulatory anesthesia. Anesthesiology [Internet]. 2009;110(5):1061-7. Available from: https:// pubmed. ncbi. nlm. nih.gov/19352161/

7. Camann W. Pain, pain relief, satisfaction and excellence in obstetric anesthesia: A surprisingly complex relationship. Anesth Analg [Internet]. 2017 Feb 1 [cited 2021 Apr 19]; 124(2):383-5. Available from: https://pubmed. ncbi.nlm.nih.gov/28098685/

8. Berning V, Laupheimer M, Nübling M, Heidegger T. Influence of quality of recovery on patient satisfaction with anaesthesia and surgery: a prospective observational cohort study. Anaesthesia [Internet]. 2017 Sep 1 [cited 2021 Apr 19];72(9):1088-96. Available from: https:// pubmed. ncbi. nlm. nih. gov/ 285 10285/

9. Benwu KM, Gebremedhin HG. A prospective study on elective surgical inpatient satisfaction with perioperative anaesthesia service at Ayder comprehensive specialized hospital, Mekelle, Ethiopia. BMC Anesthesiol [Internet]. 2019 Apr 1 [cited 2021 May 28];19(1):1-9. Available from: https:// doi.org/10.1186/s12871-019-0696-8

10. Harms C, Nübling M, Langewitz W, Kindler $\mathrm{CH}$. Patient satisfaction with continued versus divided anesthetic care. J Clin Anesth [Internet]. $2007 \mathrm{Feb}$ [cited 2021 Apr 19];19(1):9-14. Available from: https:// pubmed. ncbi. nlm. nih.gov/17321920/

11. Gempeler F, Avellaneda M. Evaluation of Patient Satisfaction and Recovery Time Following Different Anesthetic Techniques at the San Ignacio University Hospital. Rev Colomb Anestesiol [Internet]. 2010;38(2):178-202. Available from: https://www.researchgate.net/ publication/ 262437219 Evaluation of Patient Satisfaction and Recovery Time Following Different Anesthetic Techniques at the_San_Ignacio_University_Hospital

12. De los Ríos G, Cordero I, Pérez G, Mora I. Satisfacción de la recuperación anestésica postoperatoria, según escala en pacientes con anestesia general y neuroaxial. Rev Medica Hered [Internet]. 2017 [cited 2021 May 28];40 (4): 2017-264. Available from: www. medigraphic.org. mxhttp:// www. medigraphic.com $/ \mathrm{rma}$

13. Kreutziger J, Hirschi D, Fischer S, Herzog RF, Zbinden S, Honigmann P. Comparison of interscalene block, general anesthesia, and intravenous analgesia for out-patient shoulder reduction.J Anesth [Internet]. 2019 Apr 19 [cited 2021 May 29];33(2):279-86. Available from: /pmc/articles/ PMC 644 3920/

14. De Cassai A, Geraldini F, Boscolo A, Pasin L, Pettenuzzo T, Persona P, et al. General Anesthesia Compared to Spinal Anesthesia for Patients Undergoing LumbarVertebral Surgery:A Meta-Analysis of Randomized Controlled Trials. J Clin Med [Internet].2020 Dec 30 [cited 2021 May 29];10(1):102-9. Available from:https://pubmed.ncbi.nlm.nih.gov/33396744/

15. Capdevila X, Aveline C, Delaunay L, Bouaziz H, Zetlaoui P, Choquet O, et al. Factors Determining the Choice of Spinal Versus General Anesthesia in Patients Undergoing Ambulatory Surgery: Results of a Multicenter Observational Study. Adv Ther [Internet]. 2020 Jan 1 [cited 2021 May 29];37 (1):527-40.Available from:/pmc/articles/PMC6979445/

16. Arenholt L, Glavind M, Greisen S. High patient satisfaction with local anesthesia and light sedation in a novel fast-track setup for sacrospinous fixation. Female Pelvic Med Reconstr Surg [Internet]. 2020 Dec 1 [cited 2021 May 30];26(12):758-62. Available from: https://pubmed.ncbi. nlm. nih. gov/ 30865029/

17. Mracek J, Kletecka J, Holeckova I, Dostal J, Mrackova J, Mork J, et al. Patient satisfaction with general versus local anesthesia during carotid end arte rectomy. J Neurol Surgery, Part A Cent Eur Neurosurg [Internet]. 2019 [cited 2021 May 29];80(5):341-4. Available from: https:// pubmed. ncbi. nlm. nih.gov/31035296/

18. Wang H, Ma L, Yang D, Wang T, Wang Q, Zhang L, et al. Cervical plexus anesthesia versus general anesthesia for anterior cervical discectomy and fusion surgery. Medicine (Baltimore) [Internet]. $2017 \mathrm{Feb}$ [cited 2021 May 29];96(7):6119-23. Available from: https:// pubmed.ncbi.nlm. nih. gov/ 2820 29];96

19. Uzman S, Donmez T, Erdem VM, Hut A,Yildirim D, Akinci M. Combined spinalepidural anesthesia in laparoscopic appendectomy: A prospective feasibility study. Ann Surg Treat Res [Internet]. 2017 Apr 1 [cited 2021 May 29];92(4):208-13. Available from: https://pubmed. ncbi. nlm. nih. gov/ 283 82293/

20. Subramanian B, Shastri N, Aziz L, Gopinath R, Karlekar A, MehtaY, et al. ASSIST - Patient satisfaction survey in postoperative pain management from Indian subcontinent.J Anaesthesiol Clin Pharmacol [Internet]. 2017 Jan 1 [cited 2021
May 29];33(1):40-7. Available from:/pmc/articles/PMC5374829/

21. Gökçek E, Kaydu A. The effects of music therapy in patients undergoing septorhinoplasty surgery under general anesthesia. Braz J Otorhinolaryngol [Internet]. 2020 Jul 1 [cited 2021 May 29];86(4):419-26. Available from: https://pubmed.ncbi.nlm.nih.gov/31523022/

22. Kahloul M, Mhamdi S, Nakhli MS,Sfeyhi AN, Azzaza M, Chaouch A, et al. Effects of music therapy under general anesthesia in patients undergoing abdominal surgery. Libyan J Med [Internet]. 2017 Jan 13 [cited 2021 May 29];12(1):12-6. Available from: https://pubmed.ncbi. nlm. nih. gov/ 284526 $03 /$

23. Sinbukhova E, Lubnin A. A comprehensive analysis of patient satisfaction with anesthesia. Saudi J Anaesth [Internet]. 2019 Oct 1 [cited 2021 May 29];13 (4): 332-7.Available from: https:// pubmed.ncbi.nlm. nih. gov/ 3157 2078/

24. Chuang C-C, Lee C-C, Wang L-K, Lin B-S, Wu W-J, Ho C-H, et al. An innovative nonpharmacological intervention combined with intravenous patientcontrolled analgesia increased patient global improvement in pain and satisfaction after major surgery. Neuropsychiatr Dis Treat [Internet].2017 Apr 6 [cited 2021 May 28];13(5):1033-42. Available from: https://pubmed.ncbi. nlm. nih.gov/28435273/

25. Schiefer JL, Lipensky A, Fuchs PC, HeitzmannW, Schulz A. Patients' satisfaction with anesthesia in enzymatic debridement from a surgical perspective. Burns [Internet]. 2020 Aug 1 [cited 2021 May 29];46(5):1073-82. Available from: https://pubmed.ncbi.nlm.nih.gov/31901406/

26. Wazir A, Shukla A, Dutton RP. Patient Satisfaction in Anesthesia: Implementation, Relevance, and Identification of Meaningful Measures. Adv Anesth [Internet]. 2018 Dec 1 [cited 2021 May 29]:36(1):23-37. Available from:https://pubmed.ncbi.nlm.nih.gov/30414639/

27. Greimel F, Maderbacher G, Zeman F, Grifka J, Meissner W, Benditz A. No Clinical Difference Comparing General, Regional, and Combination Anesthesia in Hip Arthroplasty: A Multicenter Cohort-Study Regarding Perioperative Pain Management and Patient Satisfaction. J Arthroplasty [Internet]. 2017 Nov 1 [cited 2021 May 29];32(11):3429-33. Available from: https://pubmed.ncbi.nlm.nih.gov/28641966/

28. Kaya U ur B, Pirbudak L, Öztürk E, Balat Ö, U ur MG. Spinal versus general anesthesia in gynecologic laparoscopy: A prospective, randomized study. J Turkish Soc Obstet Gynecol [Internet].2020 Oct 2 [cited 2021 May 29];1 7 (3): 186-95. Available from:/pmc/articles/PMC7538827/

29. Stark PA, Myles PS, Burke JA. Development and psychometric evaluation of a postoperative quality of recovery score: The QoR-15. Anesthesiology [Internet]. 2013 Jun [cited 2021 May 30];118(6):1332-40. Available from: https://pubmed.ncbi.nlm.nih.gov/23411725/

30. Auquier P, Pernoud N, Bruder N, Simeoni M-C, Auffray J-P, Colavolpe C, et al. Development and Validation of a Perioperative Satisfaction Ouestionnaire. Anesthesiology [Internet]. 2005 Jun 1 [cited 2021 May 30];102(6):1116-23. Available from: https://pubs.asahq.org/anesthesiology/ article/ 102/6/ 1116/8660/Development-and-Validation-of-a-Perioperative

31. Yuksek YN, Akat AZ, Gozalan U, Daglar G, Pala Y, Canturk M, et al. Laparoscopic cholecystectomy under spinal anesthesia. Am J Surg [Internet] 2008 Apr 1 [cited 2021 May 30];195(4):533-6. Available from: http://www. americanjournalofsurgery.com/article/S0002961008000226/fulltext

32. Picola N,Torremade J, Fiol M, Fernández-Concha JJ, Beato S, Vigués F. Analysis of satisfaction and surgical outcomes of a major ambulatory surgery program for penile implant. Actas Urol Esp. 2020 Jun 1;44(5):262-7.

33. Castellanos A, Cervantes H, Vásquez P. Satisfacción anestésica como indicador de calidad de la atención médica en el paciente geriátrico. Rev Mex Anestesiol [Internet]. 2013 [cited 2021 Apr 19];36(1):250-5. Available from: www.medigraphic.org.mx

34. Urman RD, Gan TJ. Patient Satisfaction: Measuring the Association Between Anesthetic Management and Patient Experience. Anesth Analg [Internet]. 2019 Oct 1 [cited 2021 May 30];129(4):918-20. Available from: https:// pubmed.ncbi.nlm.nih.gov/31584916/

35. Meng T, Zhong Z, Meng L. Impact of spinal anaesthesia vs. general anaesthesia on peri-operative outcome in lumbar spine surgery: a systematic review and meta-analysis of randomised, controlled trials. Anaesthesia [Internet]. 2017 Mar 1 [cited 2021 May 29];72(3):391-401. Available from:https://pubmed.ncbi.nlm.nih.gov/27770448/

36. Pozdnyakova A, Tung A, Dutton R, Wazir A, Glick DB. Factors Affecting Patien Satisfaction With Their Anesthesiologist: An Analysis of 51,676 Surveys From a Large Multihospital Practice. Anesth Analg [Internet].2019 Oct 1 [cited 2021 May 30];129(4):951-9. Available from: https:// pubmed. ncbi. nlm. nih. gov/ 31206431/

37. Echevarria M, Ramos P, Caba F, López J, Almeida C, Cortes Gonzalez C. Factores determinantes de la satisfacción del paciente con la consulta de anestesia. Rev Calid Asist [Internet]. 2015 Sep 1 [cited 2021 Apr 19]; 30 (5): 215-9. Available from: https://linkinghub. elsevier.com/ retrieve/ pii/ S113 $4282 \times 15001025$ 